\author{
Evelin Gomes de Sousa Pinho
}

\title{
ACORDO DE ACIONISTAS
}

\section{Monografia}

DEPARTAMENTO DE DIREITO

Pós-Graduação em Direito de Empresas

Coordenadora Geral: Profa ${ }^{a}$ Caitlin Sampaio Nulholland 


\section{Pontificia Universidade Catollica \\ DO RIO DE JANEIRO}

Evelin Gomes de Sousa Pinho

ACORDO DE ACIONISTAS

Monografia apresentada ao Programa de PósGraduação em Direito de Empresas da PUC-Rio como requisito parcial para obtenção do título de Especialista em Direito de Empresas. Aprovada pela Comissão Examinadora abaixo assinada.

DEPARTAMENTO DE DIREITO

Coordenadora Geral: Profa ${ }^{a}$ Caitlin Sampaio Nulholland

Rio de Janeiro Outubro de 2018 
Dedico este trabalho ao meu avô Sebastião da Conceição Gomes, que me educou com muito amor e sempre me ensinou a ser uma pessoa melhor, estudiosa e honrada, e que tenho a certeza de que torce pelo meu sucesso de onde ele esteja. 


\section{Agradecimentos}

Só tenho a agradecer pela compreensão e apoio de meus familiares e amigos, que nunca me deixaram desistir e sempre me incentivaram na busca desse diploma. Em especial, agradeço minha mãe e minha avó, por terem me educado e ensinado a ser quem sou, sempre incentivando meus estudos. Agradeço também aos meus amigos, Danilo, Fernanda, Guilherme, Jenifer, Julia e Pedro, que compreenderam minha ausência e sempre me apoiaram em minha vida acadêmica. 


\section{Resumo}

PINHO, Evelin Gomes de Sousa. Direito de acionistas. Rio de Janeiro, 2017. Monografia de Especialização - Departamento de Direito, Pontifícia Universidade Católica do Rio de Janeiro.

O presente estudo tem como objeto a análise das principais características de um Acordo de Acionistas na Sociedade Anônima, levandose em consideração sua forma, natureza jurídica, partes, objeto, arquivamento e averbação. $\mathrm{O}$ texto analisa seus tipos e finalidades, a fim de compreender o objetivo de cada tipo de acordo em uma sociedade e seus benefícios aos acionistas, bem como os efeitos do acordo perante a sociedade, seus administradores e terceiros. Por fim, pretende-se analisar os diferentes entendimentos sobre seu prazo e divergências em relação à omissão do prazo, bem como os efeitos de seu descumprimento.

\section{Palavras-chave}

Acordo de acionistas; acordos de controle; acordos de voto minoritário; acordos de bloqueio; prazo; inadimplemento. 


\section{Abstract}

PINHO, Evelin Gomes de Sousa. Shareholders's Agreement. Rio de Janeiro, 2018. Monograph - Departamento de Direito, Pontifícia Universidade Católica do Rio de Janeiro.

The present study aims to analyze the main characteristics of a shareholders' agreement in the business corporation (S.A.), by considering its form, legal nature, parties, object, filing and registration. We evaluate its types and purposes in order to understand the objective of each type of agreement in the corporation and its benefits to the shareholders, besides the effects of the agreement within the company, its administrators and third parties. Finally, we analyze the different understandings about its time frame and divergences regarding the omission of the time frame, along with the effects of its non-compliance.

\section{Keywords}

Shareholders' Agreement; Control Agreement; Minority Voting Agreement; Blocking Agreement; Time Frame; Non-compliance. 


\section{Sumário}

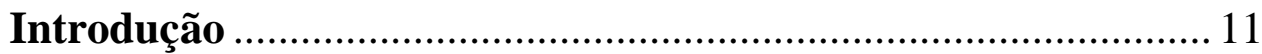

1 Conceito e principais características do acordo de acionistas na sociedade anônima 12

1.1 Natureza Jurídica 12

1.2 Partes 14

1.3 Forma 15

1.4 Arquivamento e Averbação 16

2 Tipos de acordos de acionistas. 17

2.1 Acordos de Voto 17

2.1.1 Acordos sobre Determinadas Deliberações da Assembleia Geral 19

2.1.2 Acordo de Proteção de Minoria 20

2.1.3 Acordo de Grupo Minoritário 20

2.1.4 Acordo de Joint Venture 20

2.2 Acordos de Controle .21

2.2.1 Vinculação dos Administradores 23

2.3 Acordos de Bloqueio 25 
3.1 Execução Específica ......................................................... 28

4 Prazo do acordo de acionistas............................................... 31

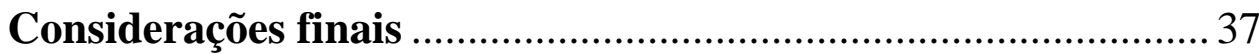

Referências bibliográficas ................................................... 39 


\section{Lista de siglas}

LSA - Lei das Sociedades Anônimas

NCPC - Novo Código de Processo Civil

CPC - Código de Processo Civil

LICC - Lei de Introdução ao Código Civil

TJ/DF - Tribunal de Justiça do Distrito Federal

TJ/RJ - Tribunal de Justiça do Estado do Rio de Janeiro

STJ - Superior Tribunal de Justiça

Resp - Recurso Especial 



\section{Introdução}

O acordo de acionistas, instituído no Direito Societário brasileiro pelo artigo 118 da LSA, com alterações introduzidas pela Lei $\mathrm{N}^{\circ} 10.303 / 2001$, foi trazido ao direito brasileiro com o objetivo de regular o exercício dos direitos e obrigações dos acionistas de uma sociedade referentes às suas ações, compondo seus interesses em relação aos seus direitos políticos e patrimoniais.

Assim, seja para proteger direitos dos acionistas minoritários, seja para manter o poder de controle da sociedade, surgiu o instituto do acordo de acionistas, para que os acionistas pudessem fazer valer suas vontades.

O que se pretende com o presente trabalho é estudar e analisar os tipos de acordo, para entender como o acordo de acionistas pode proteger os direitos dos acionistas minoritários, manter o poder de controle dos acionistas através da vinculação dos administradores eleitos nos termos do acordo de controle, e como os acordos de bloqueio podem beneficiar os acionistas da sociedade que se comprometem através da celebração deste instrumento.

Para alcançar este fim, fez-se imprescindível realizar um estudo sobre as diferentes doutrinas em relação a cada tipo de acordo, bem como o entendimento dos tribunais brasileiros sobre questões controversas relacionadas ao tema, tratando-se de uma matéria que incentiva a produção acadêmica, inclusive por se tratar de um tema com escassa jurisprudência e decisões administrativas a respeito. 


\section{Conceito e principais características do acordo de acionistas na sociedade anônima}

\section{1 \\ Natureza Jurídica}

Inicialmente, cabe aqui trazer a definição de acordo de acionistas disposta no artigo 118 da LSA, que o define como sendo um contrato entre acionistas de uma sociedade anônima, que pode versar sobre (i) a compra e venda de suas ações; (ii) preferência para adquiri-las; (iii) exercício de direito a voto; (iv) ou poder de controle, e que, uma vez arquivados na sede da sociedade, deverão ser observados pela Companhia.

Diante da definição disposta no referido artigo, faz-se necessário observar as diferentes posições doutrinárias em relação à natureza jurídica dos acordos de acionistas.

Para Celso de Albuquerque Barreto, o acordo de acionistas no direito brasileiro tem natureza jurídica de contrato, subordinado à LSA, se aplicando subsidiariamente aos princípios da legislação civil. O autor explicita que sendo um contrato típico ou nominado, com a entrada em vigor da LSA, o acordo de acionistas apresenta caráter de contrato plurilateral interno quando mais de dois acionistas estão sujeitos a direitos e obrigações em virtude do acordo.

Além disso, Celso Barreto explana que:

Apesar de frequente na doutrina italiana a atribuição de um caráter associativo ao sindicato de voto, parece-nos indubitável inexistir tal característica no acordo de acionistas introduzido no direito pátrio pela Lei $\mathrm{n}^{\circ} 6.404$ de 1976, preponderando neste o caráter contratual, regulado, subsidiariamente, pelas normas gerais da lei 
civil, aplicáveis aos contratos levando em conta as peculiaridades desse tipo de pacto e as disposições específicas da lei societária. ${ }^{1}$

Por fim, o autor define o acordo de acionistas como sendo:

[...] contratos "intuito personae", ou seja, são celebrados em razão das pessoas contratantes, acionistas ou grupos de acionistas que se unem para assegurar o controle da companhia ou para melhor assegurar seus direitos de minoritários.

O autor Carlos Augusto da Silveira Lobo², compartilha do conceito doutrinário criado por Oppo, no qual o autor defende que os acordos de acionistas são contratos parassociais, onde as partes regulam direitos e obrigações como sócios daquela sociedade e por isso são considerados como acessórios ou coligados ao contrato/estatuto social.

Em sua obra, João Luiz Coelho da Rocha ${ }^{3}$ entende que os acordos de acionistas têm natureza negocial, sendo um contrato civil e não comercial, uma vez que não se estipulam relações comerciais nos acordos, e sim, questões relacionadas à filosofia jurídica de direitos acionários.

Em contrapartida, Modesto Carvalhosa ${ }^{4}$ defende que não só as partes do acordo de acionistas, como também a própria sociedade estão vinculadas às condições ali dispostas, uma vez que o negócio jurídico produz efeitos perante todos os titulares de interesse envolvido, sendo ainda, a própria sociedade "credora da obrigação da comunhão de controlá-la consoante o

\footnotetext{
${ }^{1}$ BARRETO, Celso de Albuquerque. Acordo de Acionistas. Rio de Janeiro: Ed. Forense, 1982, p. 39.

${ }^{2}$ LAMY FILHO, Alfredo e BULHÕES PEDREIRA, José Luiz. Direito das Companhias. $2^{\mathrm{a}}$ ed. Rio de Janeiro, Forense, p. 321.

${ }^{3}$ ROCHA, João Luiz Coelho. Acordo de Acionistas e Acordo de Cotistas. Rio de Janeiro: Lumem Juris, 2002, p. 30.

${ }^{4}$ CARVAlHOSA, Modesto. Acordo de Acionistas: Homenagem a Celso Barbi Filho. $2^{\mathrm{a}}$ ed. São Paulo: Saraiva, p. 77
} 
interesse social e no estrito cumprimento de seu dever fiduciário", nos acordos de controle.

Segundo o autor, não obstante a Companhia ser credora da obrigação é também devedora de obrigações, uma vez que tem obrigação de fazer prevalecer a vontade majoritária junto aos órgãos sociais, em cumprimento aos parágrafos $8^{\circ}$ e $9^{\circ}$ do artigo 118 da LSA.

Diante disto, Modesto Carvalhosa entende que os acordos de controle não são contratos parassociais, e sim sociais, vez que produzem interesse também à Companhia.

\section{2}

Partes

De certo que em um acordo podem figurar como parte os acionistas de uma determinada sociedade. Diversos autores entendem como parte legítima em um acordo de acionistas, não só o próprio acionista, como também o usufrutuário a que tenha atribuído-se o direito de voto no ato de instituição de usufruto (artigo 114 da LSA), figurando a companhia apenas como interveniente anuente nos acordos, sendo certo que os efeitos perante a companhia, decorrem do arquivamento em sua sede, como se verificará a seguir.

Não obstante, para o autor Modesto Carvalhosa ${ }^{5}$, as partes em um acordo de acionistas são classificadas como parte em sentido formal e parte

\footnotetext{
${ }^{5}$ Ibidem, p. 31.
} 
em sentido substancial. Sendo parte em sentido formal, somente os acionistas, exceto quando se tratar de acordo de bloqueio, onde a companhia também será parte em sentido formal, nos casos em que esta for titular de direito de preferência na aquisição de ações, para mantê-las em tesouraria. Já nos acordos de controle, o autor entende ser a companhia parte em sentido substancial.

Sendo assim, em um acordo de acionistas, todas as partes devem ser titulares de ações, incluindo-se os usufrutuários e fideicomissários.

\section{3}

\section{Forma}

Embora a LSA não tenha estabelecido a obrigatoriedade de sua forma escrita, o acordo de acionistas somente produzirá efeitos em relação à terceiros e à própria companhia, se arquivados na sede desta última.

Assim, só é possível que o referido acordo tenha eficácia erga omnes se realizado na forma escrita, para que então, possa ser arquivado na sede da companhia, produzindo efeito perante todos.

Entretanto, cabe aqui ressaltar, que uma vez que a LSA não exigiu sua forma escrita, não se pode falar que o acordo realizado na forma não escrita, será nulo, sendo, neste caso, somente ineficaz perante a companhia e terceiros. 


\section{4}

\section{Arquivamento e Averbação}

Conforme brevemente mencionado acima, para que os acordos de acionistas produzam efeitos perante a sociedade e terceiros, devem, obrigatoriamente, ser arquivados na sede da companhia, bem como averbados nos livros de registro e nos certificados das ações, conforme estabelecido no caput e no $\S 1^{\circ}$ do artigo 118 da LSA.

De acordo com o autor Carlos Augusto da Silveira Lobo ${ }^{6}$, o referido arquivamento e averbação são ônus, e não deveres jurídicos, vez que diversamente da obrigação, o ônus não corresponde a qualquer pretensão de outrem, sendo apenas condição para a realização de um interesse. Neste sentido, o referido autor explana que:

[...] aquele que tem um interesse subordinado a um ônus, pode optar por não cumpri-lo, renunciando à satisfação do interesse.

O interesse condicionado ao ônus de arquivar o acordo na sede é a produção dos efeitos previstos no caput e nos $\S \S 5^{\circ}, 6^{\circ}, 7^{\circ}, 8^{\circ}, 9^{\circ}, 10$ e 11 do artigo 118 . O interesse condicionado ao ônus de averbar, nos termos do artigo 40 e seu parágrafo único, a cláusulas pertinentes nos livros de registro e certificados de ações, se houver, é a obtenção dos efeitos previstos nos $\S \S 1^{\circ}$ e $4^{\circ}$ do artigo 118 . Se os ônus não forem cumpridos, os dispositivos mencionados não se aplicam, mas os acordos de acionistas permanecem válidos, vinculando as partes.

${ }^{6}$ Apud LAMY FILHO e BULHÕES PEREIRA, op. cit., p. 344. 


\section{Tipos de acordos de acionistas}

\section{1}

\section{Acordos de Voto}

Segundo o autor Modesto Carvalhosa ${ }^{7}$, com a entrada em vigor da Lei No $^{\text {1 }} 10.303 / 2001$, que realizou alterações à LSA, os acordos de voto passaram a ser restritos ao exercício comum dos direitos políticos dos acionistas minoritários, tendo então este acordo, natureza específica, e sendo por ele denominado como acordo de voto dos minoritários.

Estes acordos podem versar sobre a eleição de administradores representantes destes acionistas minoritários, ou sobre o direito de retirada, também conhecido como direito de recesso, para que possam eleger com maioria simples, os administradores que também irão exercer a gestão da sociedade com o capital disperso.

Assim, o autor entende que estes acordos têm natureza de contrato parassocial, uma vez que seus efeitos se operam na própria sociedade, ainda que a companhia não seja a titular do direito convencionado nestes acordos, vez que não são os acionistas minoritários que comandam a sociedade à realização de seu objeto social.

\footnotetext{
${ }^{7}$ CARVALHOSA, op. cit., p. 259.
} 
Neste sentido, Modesto Carvalhosa explana que "os acordos de voto são negócios que, embora devam atender o interesse social, não vinculam a sociedade à vontade dos minoritários, expressa por meio deles".

Por fim, cabe destacar seu entendimento de que os acordos de voto são contratos plurilaterais, parassociais e baseados no affectio entre os acionistas que figuram como parte no acordo e na lealdade perante a sociedade.

Já para o autor Celso de Albuquerque Barreto ${ }^{8}$, os acordos de voto são tratados como acordos de defesa, que tem como finalidade aumentar a influência dos acionistas minoritários na sociedade unindo-se para formar um só bloco.

Celso Barreto explana que esta influência através da formação de um só bloco, pode se dar por meio do direito assegurado pela lei, ao voto múltiplo para eleição de membros do conselho de administração e através do direito concedido aos acionistas que detém pelo menos $20 \%$ do capital com direito a voto a eleger um membro do conselho.

E, por fim, vamos aqui trazer o entendimento de Carlos $\mathrm{Lobo}^{9}$, no qual o acordo de voto é o meio pelo qual o acionista se obriga para com as demais partes do acordo sobre o exercício do direito de voto do qual é titular.

Em relação ao conteúdo do voto, Carlos Lobo entende que se o conteúdo é predeterminado, a obrigação é válida, exceto se violar o dever

\footnotetext{
${ }^{8}$ BARRETO, op. cit., p. 60.

${ }^{9}$ LAMY FILHO e BULHÕES PEREIRA, op. cit., p. 331.
} 
legal do acionista, de no exercício da função de membro da assembleia, como órgão da sociedade, votar no interesse da companhia.

São comuns neste tipo de acordo, as cláusulas que estipulam a obrigação das partes signatárias de votarem em bloco, o que quer dizer que os acionistas vinculados pelo acordo votarão no mesmo sentido nas deliberações tomadas em assembleia.

As decisões de como as partes do acordo irão votar nas assembleias, poderão ser tomadas em reunião prévia, uma vez que as matérias deliberadas em assembleia são previamente elencadas no edital de convocação, sendo estas reuniões prévias realizadas somente entre os membros daquele acordo, no qual deliberarão e decidirão por maioria, como votarão para determinada deliberação, e, a minoria, ainda que não concorde com o voto, se obriga a cumprir e votar conforme o decidido na referida reunião.

Por fim, para o referido autor, os acordos de voto não estão restritos aos direitos dos acionistas minoritários, classificando este tipo de acordo em quatro modalidades, quais sejam: (i) os que tem por objeto determinada deliberação da assembleia geral; (ii) a proteção de minoria; (iii) a formação de um grupo minoritário e (iv) os de joint venture, como veremos a seguir.

\section{$\underline{2.1 .1}$}

\section{Acordos sobre Determinadas Deliberações da Assembleia Geral}

Estes acordos podem ser contratos unilaterais, bilaterais ou plurilaterais, conforme explana Carlos Lobo, senão vejamos:

[...] os unilaterais em geral ocorrem quando os órgãos da administração ou o acionista controlador procuram obter que os outros acionistas se obriguem a aprovar proposta que pretendem submeter à Assembleia Geral. 
[...] os acordos de dois ou mais acionistas sobre determinadas deliberações da assembleia são usuais quando os acionistas se obrigam a votar em certa chapa de candidatos a órgãos da administração; a distribuir de certo modo seus votos em eleição de membros do Conselho de Administração pelo processo de voto múltiplo; ou aprovar determinada proposta de distribuição de dividendos, destinação do lucro do exercício, resgate de ações, aumento de capital, emissão de valores mobiliários etc.

\section{1 .2}

\section{Acordo de Proteção de Minoria}

Para o autor Carlos Lobo, estes acordos são realizados entre o acionista controlador ou sociedade controladora e os acionistas minoritários com a finalidade de obrigar o controlador a não votar nas matérias definidas no acordo sem anuência dos minoritários; a votar de uma determinada maneira em relação a algumas matérias; a assegurar ao grupo minoritário participação nos órgãos da administração e etc.

\section{$\underline{2.1 .3}$}

\section{Acordo de Grupo Minoritário}

Nestes acordos de votação em bloco, que são plurilaterais, se forma um grupo de acionistas minoritários a fim de aumentar a influência nas deliberações.

\section{1 .4}

\section{Acordo de Joint Venture}

Tem como finalidade a associação de duas ou mais sociedades para realizarem um empreendimento comum, através da constituição de uma nova sociedade, normalmente constituída na forma de sociedade anônima. Neste caso, não há acionista controlador e minoritário. 


\section{2}

\section{Acordos de Controle}

Inicialmente, há de se destacar o entendimento do autor Carlos Lobo ${ }^{10}$ sobre os acordos de controle, que explicita que o acordo de controle tem por objetivo o exercício do poder de controle da companhia, sendo a fonte do poder de controle, a titularidade permanente da maioria dos votos nas deliberações da Assembleia Geral, sendo o conjunto das ações que conferem esta maioria de votos, denominada "bloco de controle".

Este "bloco de controle", acima referido, segundo o autor, é formado pela reunião das ações em um mesmo patrimônio de uma pessoa física ou jurídica, ou em caso de ações que integrem o patrimônio de diversas pessoas, pela vinculação, mediante celebração dos acordos de voto, vez que o artigo 116 da LSA, prevê expressamente a possibilidade de se ter um acionista controlador por meio de acordo de voto, senão vejamos:

Art. 116. Entende-se por acionista controlador a pessoa, natural ou jurídica, ou o grupo de pessoas vinculadas por acordo de voto, ou sob controle comum, que:

a) é titular de direitos de sócio que lhe assegurem, de modo permanente, a maioria dos votos nas deliberações da assembleia-geral e o poder de eleger a maioria dos administradores da companhia; e

b) usa efetivamente seu poder para dirigir as atividades sociais e orientar o funcionamento dos órgãos da companhia. [...]

Carlos Lobo explana que os acordos de controle serão sempre acordos de voto, no entanto, se distinguem, pois o poder de controle não se exerce somente pelo direito de voto nas assembleias gerais, mas também pelo fato

${ }^{10}$ LAMY FILHO e BULHÕES PEREIRA, op. cit., p. 335. 
de o acionista controlador orientar os órgãos da companhia sobre o funcionamento desta última ainda que fora das assembleias.

Para o autor, os acordos de controle podem ser divididos em duas espécies, sendo que na primeira espécie, são partes do acordo diversas pessoas que detenham determinada quantidade de ações insuficientes para assegurar o poder de controle, que se unem através do acordo para formar um bloco de controle, exercendo, assim, o poder de controle conjuntamente. Já a segunda espécie, ocorreria nos casos em que o acionista proprietário do bloco de controle celebra o acordo com outros acionistas para exercício em comum do poder de controle, sendo, esta segunda espécie, pouco utilizada na prática.

Cabe aqui trazer, o posicionamento do autor Celso Barreto ${ }^{11}$, que denomina o acordo de controle como acordo de comando, definindo-o como:

[...] aqueles pelos quais grupos de acionistas que, isoladamente, não deteriam o controle da companhia, mas que, em conjunto, passam a ter o controle e se unem através de acordo de comando e bloqueio, para assegurar o controle e garantir os direitos dos participantes.

Para Celso Barreto, estes acordos geralmente têm como objeto, a forma de escolha dos administradores da companhia, o campo de atuação desta última, abertura e encerramento de filiais, deliberações sobre alterações estatutárias deliberações sobre empréstimos e financiamentos e etc.

Nota-se que, tanto para o autor Celso Barreto quanto para Carlos Lobo, os acordos de controle, sendo para este último autor, tratado somente na primeira espécie do acordo, instrumentos onde acionistas que somente com suas ações com direito a voto, não seriam capazes de exercer o poder de

\footnotetext{
${ }^{11}$ BARRETO, op. cit., p. 58.
} 
controle da companhia, unindo-se então, através deste instrumento, para que conjuntamente, possam exercer o poder de controle, que será realizado por meio da forma de escolha dos administradores, bem como através de orientações realizadas fora de assembleias gerais.

Por fim, passaremos a analisar o entendimento do autor Modesto Carvalhosa ${ }^{12}$, inicialmente trazendo seu conceito sobre controle societário, no qual o controle societário é poder de direito de dirigir as atividades sociais, sendo o controle o poder efetivo de direção dos negócios sociais, em sentido material e não apenas formal, sendo controlador, aquele que exerce, de direito, o poder, por meio do prevalecimento permanente de votos e por outros fatores extrassocietários.

Assim, o autor entende que o controle da companhia é um poder autônomo e legalmente instituído de impor a vontade do controlador nos atos sociais, e consequentemente, dirigir a sociedade para consecução de seu objeto social.

\section{$\underline{2.2 .1} \underline{\text { Vinculação dos Administradores }}$}

Com a redação trazida pelo $\S 8^{\circ}$ do artigo 118 da LSA, depreende-se que o legislador quis vincular os administradores aos acordos de acionistas, vez que estabeleceu que os votos proferidos em desacordo com o acordo de

${ }^{12}$ CARVAlHOSA, op. cit., p. 209. 
acionistas não seriam computados pelo presidente da assembleia ou pelo órgão colegiado de deliberação da companhia.

Neste sentido, leciona Modesto Carvalhosa ${ }^{13}$ que os acordos de controle vinculam não somente os acionistas que o integram, como também os administradores indicados pela comunhão de controle, bem como os diretores, vez que a diretoria tem competência originária sobre todos os assuntos da administração, além de ser um órgão colegiado, vez que exerce função deliberativa.

Desta forma, nas companhias que tiverem conselho de administração, o acordo vinculará os conselheiros e também os diretores, e nos casos em que a companhia não tiver conselho de administração, vinculará a diretoria.

Neste sentido, entendeu o TJ/DF, senão vejamos:

AÇÃO ANULATÓRIA DE ATO JURÍDICO - ANULAÇÃO DE ATA PRELIMINAR DE DESERÇÃO COM RELAÇÃO A UM DOS RECURSOS CUSTAS RECOLHIDAS APÓS A INTERPOSIÇÃO DA APELAÇÃO ACORDO DE ACIONISTAS - EFICÁCIA - PROVIDÊNCIAS LEGAIS VINCULAÇÃO DOS

CONSELHEIROS AO ACORDO DE ACIONISTAS - PROCURAÇÃO OUTORGADA POR CONSELHEIRO PARA O EXERCÍCIO DO VOTO POSSIBILIDADE. 1. NÃO SE CONHECE DA APELAÇ̃̃O SE AS CUSTAS RELATIVAS AO SEU PROCESSAMENTO FORAM RECOLHIDAS POSTERIORMENTE À INTERPOSIÇÃO DO RECURSO, NÃO CONSTITUINDO MOTIVO DE FORÇA MAIOR A CIRCUNSTÂNCIA DE AS AGÊNCIAS BANCÁRIAS ENCERRAREM AS ATIVIDADES ANTES DO EXPEDIENTE FORENSE, HAJA VISTA A NOTORIEDADE DO FATO. 2. O ACORDO DE ACIONISTAS É UM CONTRATO REGULADO PELA LEI, QUE EXIGE PROVIDÊNCIAS A FIM DE QUE A SUA EFICÁCIA NÃO SE LIMITE ÀS PARTES ACORDANTES, COMO O ARQUIVAMENTO DO AJUSTE NA SEDE DA COMPANHIA E A AVERBAÇÃO DO MESMO NOS LIVROS DE REGISTROS E NOS CERTIFICADOS DAS AÇÕES (LEI 6404 /76, ART. 118, $\left.\S 1^{\circ}\right)$. 3. APESAR DE NÃO TER SIDO EFETIVADO O ARQUIVAMENTO E A AVERBAÇÃO DO ACORDO DE ACIONISTAS NA FORMA LEGAL,

${ }^{13}$ CARVALHOSA, op. cit., p. 211. 
MOSTRA-SE INCONGRUENTE QUE OS APELANTES, PARA ATINGIR A MAIORIA DOS VOTOS PERSEGUIDA, PRETENDAM AFASTAR A APLICAÇÃO DO AJUSTE NA PARTE EM QUE OS OBRIGA A VOTAR EM BLOCO, MAS, EM VIA DIAMETRALMENTE OPOSTA, DELE DEPENDAM PARA GARANTIR QUE OS CONSELHEIROS INTEGREM O CONSELHO DE ADMINISTRAÇÃO. 4. A NOVA REDACÃO DO ART. 118 DA LEI 6404/76 COLOCOU UMA PÁ DE CAL NAS DISCUSSÕES SOBRE A VINCULACÃO DOS CONSELHEIROS AO ACORDO DE ACIONISTAS,

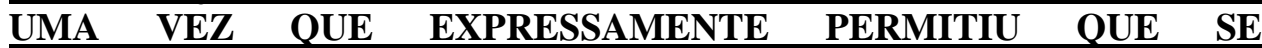
DESCONSIDERASSEM OS VOTOS POR ELES PROFERIDOS, QUANDO EM CONTRARIEDADE COM O AJUSTE. 5. INEXISTE ÓBICE DE QUE OS CONSELHEIROS OUTORGUEM PROCURAÇÃO PARA QUE O EXERCÍCIO DE VOTO SE DÊ POR MEIO DE REPRESENTANTE, HAJA VISTA QUE NÃO HÁ EXIGÊNCIA LEGAL DE QUE REFERIDOS ATOS SEJAM PRATICADOS PESSOALMENTE. 6. NEGADO PROVIMENTO AO APELO. (TJ-DF APELAÇÃO CÍVEL AC 377702420018070001 DF 0037770-24.2001.807.0001 (TJ-DF)

\section{3}

\section{Acordos de Bloqueio}

Os Acordos de Bloqueio para Celso Barreto ${ }^{14}$, tem como objetivo assegurar estabilidade através da opção ou preferência em favor dos acionistas que integram o acordo na aquisição das ações do sócio retirante.

Ressalta-se que este tipo de acordo não tem a finalidade de impedir a venda das ações para determinados acionistas, e sim, estipular a preferência que deve ser dada aos remanescentes, estipulando-se o preço de venda, bem como manter a unidade do grupo que resolveu adotar determinada orientação das assembleias gerais da companhia.

Ademais, o autor explana o seguinte: "Os acordos de bloqueio visam, assim, manter os acionistas que deles participam em posições estáveis, a fim de que sejam mantidos o equilíbrio e a solidez da convenção".

\footnotetext{
${ }^{14}$ BARRETO, op. cit., p. 57.
} 
De acordo com o autor Modesto Carvalhosa ${ }^{15}$, os acordos de bloqueio (preferência e opção) têm natureza jurídica diferente dos acordos de voto dos minoritários, pois predomina a unilateralidade das relações negociais.

Para Modesto Carvalhosa, estes acordos têm como objeto a compra e venda de ações e títulos conversíveis em ações, em virtude do exercício do direito de preferência ou de opção na aquisição desses valores mobiliários.

Segundo Modesto Carvalhosa, a natureza deste acordo caracteriza-se da seguinte forma: "os pactos de bloqueio são de natureza unilateral clássica, dependendo a sua validade e eficácia da existência da companhia e de artigos estatutários compatíveis, residindo aí a sua acessoriedade”.

Assim, estes acordos não seriam plurilaterais uma vez que o interesse das partes seria contrastante, sendo a avença resolvida pela cláusula resolutiva implícita.

Neste sentido, o autor divide os acordos de bloqueio em:

(i) de preferência, no qual se estipula que a parte que queira vender se obriga a comunicar aos demais beneficiários sua intenção de vender as ações objeto do acordo;

(ii) opção de compra e de venda, no qual uma parte promete alienar a outros signatários do acordo, ou à própria sociedade, suas ações, ou, a promessa dos signatários ou da própria sociedade de adquiri-las;

(iii) tag along - pacto de venda conjunta, no qual o acionista minoritário tem a faculdade de vender suas ações com deságio de $20 \%$ em oferta pública, no caso de alienação de controle, cabendo aqui ressaltar que tal direito já se encontra previsto no artigo 254-A da LSA, desta forma, o artigo 118 da LSA somente permite a inclusão desta cláusula nos acordos de bloqueio;

(iv) drag along - pacto de compra conjunta, no qual caso o acionista controlador receba uma proposta de aquisição de controle, este poderá exigir que os

${ }^{15}$ CARVALHOSA, op. cit., p. 271. 
minoritários participantes do acordo, também vendam suas ações, pelo preço da oferta aceito pelo controlador; e

(v) bring along - obrigação de venda em bloco de ações, em companhias com capital disperso, no qual o grupo minoritário dominante compromete-se a vender as suas ações caso outros grupos minoritários integrantes do acordo tragam uma proposta de aquisição subscrita por um terceiro interessado na aquisição desse maior bloco de ações que permite aos seus titulares, aleatoriamente, eleger administradores.

Por fim, o acordo de bloqueio, denominado por Carlos Lobo ${ }^{16}$ como acordo sobre ações, é tratado como um pacto acessório de convenção de voto, que tem como objetivo trazer estabilidade ao grupo de acionistas que se comprometem a votar em comum, criando para as partes, direitos e obrigações relativos à alienação, aquisição ou criação de ônus reais sobre as ações da companhia.

\section{Carlos Lobo classifica este acordo em quatro grupos, sendo eles:}

(i) acordos de preferência, entendendo-se como aqueles que conferem às partes contratantes direito de preferência para adquirir as ações que uma delas pretende alienar;

(ii) de promessa ou opção de compra ou venda, podendo compreender o contrato preliminar de compra e venda, a opção de compra ou de venda, o acordo de venda em conjunto e o acordo de comprar ou vender;

(iii) de consentimento prévio, nos quais as partes se comprometem a só vender suas ações após o potencial comprador ter sido aprovado pelas demais partes; e

(iv) de vedação à alienação das ações, que são considerados legítimos pelo autor, desde que vigore por prazo razoável e seja justificado em face de cada circunstância, não podendo ser abusivo. Acrescenta o autor, que esta vedação é justificada em acordos de acionistas referentes à joint venture, em razão de sua natureza que requer conhecimento técnico para sua implantação.

${ }^{16}$ Apud LAMY FILHO e BULHÕES PEREIRA, op. cit., p. 337. 


\section{3 \\ Inadimplemento do acordo de acionistas}

\section{1}

\section{Execução Específica}

Conforme leciona Carlos $\mathrm{Lobo}^{17}$, há duas formas de execução forçada: a específica e a por compensação indenizatória. Nesta segunda forma, a obrigação é satisfeita através da expropriação e liquidação dos bens do devedor a fim de promover uma indenização em dinheiro ao credor, já na execução específica, a satisfação da obrigação é realizada mediante a entrega da própria prestação que deveria ser cumprida voluntariamente pelo devedor e não foi.

O autor explica que nos acordos de acionistas, a obrigação será sempre de fazer ou não fazer, elencando o seguinte rol:

(i) de concluir um contrato ou de abster-se de concluí-lo (compra e venda de ações ou preferência para adquiri-las; (ii) de emitir declaração de vontade ou abster-se de emiti-la (exercício de direito de voto ou do poder de controle em assembleia; ou ainda (iii) de praticar atos (exercício do poder de controle na direção das atividades sociais e orientação do funcionamento dos órgãos da companhia). Também os efeitos reflexos do acordo de acionistas arquivado na sede da companhia obrigamna a prestações de fazer ou de não fazer.

No CPC de 1973, a execução específica era tratada em seu artigo 461, no entanto, somente a partir da Lei $\mathrm{N}^{\mathrm{o}} 8.952 / 1994$, que a execução específica passou a ser tratada como regra, e a condenação em perdas e danos passou a ser tratada como exceção. Ademais, o NCPC de 2015, manteve a regra trazida pela Lei $\mathrm{N}^{\circ} 8.952 / 1994$. 
Neste mesmo sentido, se posicionou o TJ/RJ, como veremos a seguir:

TJ RJ - Apelação Cível. Execução de obrigação de não fazer. Pedido alternativo de anulação das decisões tomadas em Assembléias Gerais de Acionistas. Acordo de acionistas. Natureza jurídica e eficácia. Tendo o acordo de acionistas natureza de negócio jurídico plurilateral, submete-se às regras gerais da teoria dos contratos, tornando-se obrigatórias as condutas ali disciplinadas. Seu descumprimento importa na anulação das decisões tomadas ao seu arrepio. Provimento do recurso. (Apelação - Processo No 2005.001.14620 - Órgão Julgador: Décima Câmara Cível - Relator: Des. Sylvio Capanema - Data do julgamento: 22/11/2005)

Também reconhecendo a execução específica como meio capaz de satisfazer a prestação que deixou de ser cumprida, entendeu o STJ, senão vejamos:

STJ - Processo Civil. Execução de contrato de compra e venda de ações, com cláusula de recompra, inadimplido nesta parte. Possibilidade de execução específica do compromisso de recompra de ações que, suprindo a declaração de vontade do adquirente (obrigação de fazer), autorize a cobrança do preço (obrigação de dar); arts. 632 e 633 do Código de Processo Civil. Recurso especial não conhecido. (Resp 856826/DF - Recurso Especial - 2006/0117024-6 Relator(a) Ministra Nancy Andrighi - Relator para o Acórdão Ministro Ari Pargendler - Órgão Julgador Terceira Turma - Data do Julgamento 19/02/2008 Data da Publicação/Fonte DJE 05/11/2008).

Em relação à legitimidade para propor a execução específica, decidiu o STJ ser a companhia também parte legítima pra propositura da ação, vez que os efeitos de seu descumprimento também impactam na sociedade, conforme se verifica abaixo:

STJ - Recurso Especial. Direito processual civil e direito societário. Acordo de acionistas. Execução específica de obrigações de fazer e de entregar coisa certa. (...) - A sociedade também tem legitimidade passiva para a causa em que se busca o cumprimento de acordo de acionistas, porque terá que suportar os efeitos da decisão; como na espécie em que o cumprimento do acordo implicaria na cisão parcial da sociedade. Recursos especiais não conhecidos. (Processo RESP 784267/RJ - Recurso Especial 2005/0159503-0 - Relatora Ministra Nancy Andrighi - Órgão Julgador: Terceira Turma - Data do Julgamento 21/08/2007 - Data da Publicação/Fonte DJ 17/09/2007 p. 256).

Cabe aqui trazer o entendimento de Clóvis Bevilácqua:

[...] a obrigação de fazer não pode ser cumprida, violentando-se a vontade do indivíduo, manu militari, a praticar o ato prometido. Se ele se recusa a executar a prestação, que somente por ele podia ser executada, não é lícito forçá-lo, nem seria muitas vezes possível. 
Por fim, leciona Modesto Carvalhosa ${ }^{18}$ que a tutela específica é promovida em processo de conhecimento, mediante sentença final constitutiva transitada em julgado, acreditando que a expressão "execução específica" tenha sido mal empregada, uma vez que não se pode propor uma execução para obrigar um acionista a fazer ou deixar de fazer o que pactuou no acordo.

Neste sentido, o autor explana o seguinte:

Não se trata de execução do acordo de acionistas, tampouco de sentença ou decisão condenatória. O que existirá é um comando judicial ou arbitral em processo de conhecimento substitutivo da vontade da parte (sentença ou decisão arbitral constitutiva transitada em julgado), o qual dispensará ulterior processo executivo.

Em relação aos acordos de bloqueio, o autor explana que a sentença transitada em julgado não tem efeito real, pois a posse das ações dependerá de pedido autônomo, sendo o efeito da sentença de natureza obrigacional.

Modesto Carvalhosa explica ainda, que os acordos de acionistas de controle, de voto minoritário ou controle, de compra e venda de ações (opção ou preferência) não são títulos executivos extrajudiciais.

Por fim, traz-se aqui o entendimento do autor sobre a execução específica do acordo de acionistas:

Trata-se, portanto, a execução específica de acordo de acionistas (de controle, de voto minoritário e de compra e venda de ações regulares), de um procedimento judicial ou arbitral de cognição plena e exauriente, completamente diverso, portanto, da tutela sumária, antecipada, ou cautelar, que é incompatível com a sua natureza.

${ }^{18}$ CARVAlHOSA, op. cit., p. 327. 


\section{4}

\section{Prazo do acordo de acionistas}

De acordo com o $\S 6^{\circ}$ do artigo 118 da LSA, com redação acrescida pela Lei $N^{\circ} 10.303 / 2001$, os acordos de acionistas em que o prazo for fixado em função de termo ou condição resolutiva somente poderão ser denunciados segundo suas estipulações.

Assim, entende-se que o referido parágrafo quis estabelecer que se o prazo do acordo de acionistas for estipulado em função de uma data futura, qual seria o termo certo, ou a um evento que não se sabe quando ocorrerá, mas que seu acontecimento é certo, qual seria o termo incerto, ou ainda ao acontecimento de um evento que poderá ou não ocorrer, qual seria a condição resolutiva, a resilição unilateral será vedada antes da ocorrência de tais eventos, exceto se estabelecido de forma contrária no acordo de acionistas.

Cabe ressaltar que a parte infratora desta condição poderá incorrer em perdas e danos, bem como à execução específica anteriormente tratada.

De acordo com o autor João Luiz Coelho da Rocha ${ }^{19}$, nos acordos de acionistas sem prazo determinado, ou seja, que vigoram por prazo indeterminado, se aplica o princípio geral do direito civil, no qual os contratos celebrados por prazo indeterminado podem ser rescindidos a qualquer tempo, mediante aviso prévio.

No entanto, o autor ressalta que a rescisão imotivada mediante simples aviso prévio pode ser contestada, vez que outros doutrinadores entendem que

\footnotetext{
${ }^{19}$ ROCHA, João Luiz Coelho. Acordo de Acionistas e Acordo de Cotistas. Rio de Janeiro: Lumem
} Juris, 2002, p.75 
para a quebra contratual deve haver necessário motivo justo, entendimento este, que João Luiz Coelho da Rocha também entende como consistente, por ter o acordo de acionistas um caráter casual, e, além disso, pelo fato dos acordos de acionistas buscarem, de acordo com ele, não um esquema conjuntural episódico, mas sim uma determinada estruturação de direitos acionários que devem prevalecer enquanto seus influxos causais dominantes permanecerem.

Ademais, o autor traz em sua obra, uma decisão do TJ/RJ, de Relatoria do Desembargador Sylvio Capanema, entendendo pela razoabilidade da rescisão mediante simples aviso prévio, se o acordo vigorar por prazo indeterminado, conforme se verifica abaixo:

Ação ordinária. Revelia. Acordo de acionistas. Não se conta em dobro o prazo para contestação se os réus têm o mesmo advogado, e o outro ficou revel, não se aplicando a regra do art. 191 do CPC. O acordo de acionistas, celebrado por prazo indeterminado, só pode ser unilateralmente denunciado mediante notificação premonitória aos demais acionistas, sendo nula a deliberação tomada em assembléia realizada ao arrepio do que ficou avençado no acordo. Os juros de mora se contam a partir das assembléias irregulares já que se trata de ilícito civil. Desprovimento do apelo. (TJ-RJ, Apelação Cível no 1999.0001.02845, 10ª Câmara Cível, decisão unânime, em 18/5/1999, Rel. Des. Sylvio Capanema).

Por fim, o autor explana que, decorrido o prazo do acordo de acionistas pactuado por prazo determinado, cessa, ao final de seu prazo, a menos que todas as partes decidam continuá-lo, trazendo neste sentido, a seguinte decisão da $9^{\mathrm{a}}$ Câmara Cível do TJ/RJ:

Ação Cautelar. Decisão que defere parcialmente liminar para revigorar acordo de acionistas já resilido pelo decurso do tempo. Alegação de vício de vontade. Cassação da liminar. Agravo regimental. Não pode o judiciário, sem relevante razão de direito, e prova de prejuízo irrecuperável, ou de difícil reparação, intervir em acordo de acionistas, revigorando o já resilido ou estabelecendo regras. Pena de ofensa a princípio constitucional consubstanciado no artigo $5^{\circ}$, caput e inciso XXII, da Carta Magna de 88. Improvimento do primeiro e provimento parcial do segundo agravo, ficando prejudicado o agravo regimental. (TJ-RJ, 9 ${ }^{\mathrm{a}}$ Câmara Cível, Agravo de Instrumento no 2000.002.09024, julgamento em 12/9/2000). 
Para o autor Carlos $\mathrm{Lobo}^{20}$, uma vez que o $\S 6^{\circ}$ do artigo 118 da LSA somente tratou da questão do prazo do acordo de acionistas, para esclarecer que quando fixado em função de termo ou condição resolutiva, o acordo somente pode ser denunciado segundo suas estipulações, demais questões referente ao prazo dos acordos, serão regidos pelas normas de Direito Civil a respeito dos contratos.

O autor explana que a LSA estabeleceu expressamente que o termo ou a condição resolutivos são formas de se estabelecer um prazo para o acordo, e sendo assim, não poderiam ser resilidos unilateralmente pelas partes do acordo, antes da ocorrência do termo ou condição resolutivas.

Em relação à omissão quanto ao prazo de vigência, Carlos Lobo explicita que "não precede concluir que os acordos omissos quanto ao prazo de vigência são por prazo indeterminado, sob o fundamento de que ninguém pode obrigar-se perpetuamente”.

Não se nega o preceito sobre o caráter necessariamente temporário dos contratos. Rejeita-se, todavia, o raciocínio maniqueísta que, diante de um contrato sem prazo de vigência, conclui que as partes quiseram obrigar-se perpetuamente (o que é defeso) ou por prazo indeterminado. Em se tratando de acordo de acionistas, é muito mais razoável concluir que as partes quiseram obrigar-se enquanto se mantivessem as condições básicas que as conduziram a celebrar o pacto.

${ }^{20}$ Apud LAMY FILHO e BULHÕES PEDREIRA, op. cit., p. 354. 
O autor menciona o entendimento de Carlos Orcesi da Costa, que entende que se fosse permitida a denúncia vazia nos acordos de acionistas que versam sobre a restrição de circulação de ações, tais pactos seriam "papeluchos inúteis", as partes do acordo poderiam optar por não fazer, simplesmente notificando sua resilição unilateral e se desobrigando ao pactuado.

Por fim, em relação aos acordos de acionistas de longa duração, o autor tem posicionamento diferente de Modesto Carvalhosa, que veremos de forma mais detalhada a seguir, mas que entende que acordos celebrados por prazo superior a cinco anos em companhias abertas e nas companhias fechadas, por prazo superior a dez anos, devem ser considerados por prazo indeterminado. Sendo assim, Carlos Lobo se manifestou no sentido de que:

Cabe, então, mais uma vez, repetir a advertência, agora nas palavras de Alfredo Lamy Filho (José Luiz Bulhões Pedreira; Alfredo Lamy Filho, ob. cit., p. 314), citando Darcy Bessone: “...em matéria de acordo de acionistas seria necessário analisar o teor e sentido das cláusulas do documento para investigar se a intenção das partes não terá sido de preservar a duração, no tempo...”

Para Modesto Carvalhosa ${ }^{21}$, é possível a celebração de acordos de acionistas, tanto de voto dos minoritários como de controle, por prazo indeterminado, sendo a celebração por prazo indeterminado incompatível com os acordos de preferência e de opção. Isto porque, o autor acredita que a indeterminação do prazo é incompatível com a natureza do direito e da obrigação respectiva, citando como exemplos o acordo de opção e o direito de prelação por prazo indeterminado, totalmente incompatível com o que se pretende.

\footnotetext{
${ }^{21}$ CARVALHOSA, op. cit., p. 63.
} 
Explana o autor que os acordos de controle e voto dos minoritários estão sujeitos à resilição unilateral motivada, desde que declarada em juízo arbitral ou estatal, entendendo como causas para a dissolução motivada:

[...] Se, porém, a avença for por prazo indeterminado, sua dissolução será sempre motivada, ou seja, pela quebra da affectio ou por deslealdade ou, ainda, por tempo excessivo que descaracterize o seu objeto. Nesses casos, como reiterado, a dissolução parcial ou total do acordo de controle ou de voto minoritário deve ser sentenciada, mediante processo de conhecimento, no foro judicial ou arbitral.

Ademais, traz-se aqui o entendimento de Modesto Carvalhosa quanto ao termo e condição, que explicita que a fixação do prazo final nos acordos configura-se pela data de expiração acordada, ou através da vinculação de seu fim à ocorrência de um evento previsível, que o autor determina como termo, ou imprevisível, determinado pelo autor como condição. Senão vejamos:

Assim, termo ou condição subordinando à vigência do acordo de acionistas equivale a prazo. Nessa hipótese, embora não haja prazo determinado, existe o prazo de duração determinável pela ocorrência de um acontecimento previsto, tal qual. v.g., alteração das participações acionárias das partes convenentes abaixo de certo percentual, a perda do controle etc.

Por fim, em relação à resilição do acordo de acionistas, se posicionou

o STJ da seguinte forma:

RECURSO ESPECIAL - EMBARGOS DE DECLARAÇÃO - QUESTÃO PREJUDICIAL - ALIENAÇÃO DE PARTICIPAÇÃO SOCIETÁRIA SUCESSÃO PROCESSUAL - ART. 42 DO CPC - CONSENTIMENTO DA RÉ - DENEGAÇÃO - LEGITIMIDADE ATIVA ORIGINÁRIA - MANUTENÇÃO SUBSTITUIÇÃO PROCESSUAL - ASSISTÊNCIA LITISCONSORCIAL ADMISSIBILIDADE - RESOLUÇÃO DE ACORDO DE ACIONISTAS ANTECIPAÇÃO DE TUTELA - AUSÊNCIA DE INTERESSE DECLARATÓRIOS - OMISSÃO - DEFICIÊNCIA DE FUNDAMENTAÇÃO INOCORRÊNCIA - PRINCÍPIO GERAL DE DIREITO - ALEGAÇÃO NOVA INVIABILIDADE - EFEITOS INFRINGENTES - EMBARGOS REJEITADOS.

1. Questão de ordem pública cuja análise se antecipa, ante a prejudicialidade quanto ao exame dos Declaratórios. Ausente a aquisição, por PETROQUISA, da própria empresa PRIMERA e, em consequiência, sua extinção por incorporação ou fusão, remanesce íntegra sua personalidade jurídica, afastando-se a hipótese de sucessão processual obrigatória (art. 43 do CPC). Ao adquirir ações integrantes do capital da TRIUNFO, antes pertencentes a PRIMERA, sub-rogou-se PETROQUISA nos 
direitos decursivos destes valores mobiliários, notadamente, de participar e resolver o respectivo acordo de acionistas; destarte, alterada a titularidade da relação jurídica material, impõe-se a observância do art. 42 do CPC, pelo qual, in casu: a) inviabiliza-se a sucessão processual de PRIMERA por PETROQUISA ante o não consentimento de PETROPLASTIC (art. 42, § $1^{\circ}$, do CPC); b) mantémse a legitimidade ativa da alienante PRIMERA para prosseguir no feito em substituição processual à adquirente PETROQUISA, indeferindo-se a extinção do feito sem exame de mérito por perda superveniente de interesse de agir e legitimidade (art. 267, VI, do CPC); c) admite-se o ingresso de PETROQUISA no pleito de resolução do acordo de acionistas como assistente litisconsorcial de PRIMERA contra PETROPLASTIC, no estado em que se encontra.

2. Ainda previamente à análise dos Aclaratórios, impõe-se o indeferimento do pleito de antecipação de tutela (art. 273, I e II, do CPC) para suspensão dos efeitos de cláusula do acordo de acionistas, por ausência de interesse processual. Deferida liminar em Cautelar - $\mathrm{n}^{\circ} 1.245 / \mathrm{RS}$-, para "suspender a prática de atos que configurem a execução provisória do julgado local, até que se julgue o recurso especial por esta Corte", inviabilizou-se a produção de efeitos pelo acórdão de origem, resolutivo do acordo de acionistas da TRIUNFO; julgado, porém, o Especial aos 13.05.2003, a Cautelar perdeu seu objeto, porque pugnava, unicamente, pela concessão de efeito suspensivo àquele, determinando-se, nesta assentada (07.12.2006), sua extinção. Cessando a suspensão dos efeitos do aresto originário, confirmado por esta Corte, adquire eficácia a desconstituição do acordo de acionistas, falecendo interesse ao pleito de antecipação de tutela que visava justamente à retirada de efeitos de cláusula do acordo cuja resolução passa a vigorar. 3. Inocorre omissão e, pois, nulidade por deficiência de fundamentação do aresto que motivadamente expôs as razões de não conhecimento do Especial, admitindo "a resolução do acordo de acionistas por inadimplemento das partes, ou de inexecução em geral, bem como pela quebra da affectio societatis, com suporte na teoria geral das obrigações". Além de prescindível a explicitação do artigo de lei no qual contido o Direito aplicado à espécie, in casu, é expresso o aresto quanto à incidência de princípios gerais de Direito para o deslinde da controvérsia, conforme imposto pelos arts. $4^{\circ}$ da LICC e 126 do CPC, quando necessária a integração do Direito face a lacunas legais. Precedente. Ao aduzir suposta afronta ao art. $118, \S 6^{\circ}$, da Lei $n^{\circ} 6.404 / 76$, a embargante ignorou a natureza uniformizadora desta Corte, pelo que necessário o prequestionamento; não ventilado o dispositivo no aresto de origem, nem sequer aduzido na peça do Especial, tem-se alegação nova, cujo exame é inviável, porquanto defeso inovar em Aclaratórios. Precedentes. Não caracterizadas as estritas hipóteses do art. 535 do CPC, autorizadoras do acolhimento dos Declaratórios, resta nítida a pretensão infringente da embargante, visando ao reexame da causa, aspiração inviável, ausentes omissão, obscuridade ou contradição. Embargos rejeitados. Acórdão. Vistos, relatados e discutidos estes autos, acordam os Srs. Ministros da QUARTA TURMA do Superior Tribunal de Justiça, na conformidade dos votos e das notas taquigráficas a seguir, por unanimidade, em rejeitar os Embargos de Declaração, nos termos do voto do Sr. Ministro Relator, com quem votaram os Srs. Ministros HÉLIO QUAGLIA BARBOSA, MASSAMI UYEDA e CÉSAR ASFOR ROCHA. Impedido o Sr. Ministro ALDIR PASSARINHO JUNIOR. (Superior Tribunal de Justiça STJ - EMBARGOS DE DECLARAÇÃO NO RECURSO ESPECIAL : EDcl no REsp 388423 RS 2001/0169839-0) 


\section{Considerações finais}

Com o presente estudo, que teve como objeto a análise do acordo de acionistas, levando-se em consideração suas características e alcance, pôdese observar a importância deste instituto na defesa dos interesses dos acionistas que participam do acordo.

Nota-se que há uma divergência na doutrina sob sua natureza jurídica, entendida em parte como pacto parassocial, uma vez que suas partes buscam regular direitos e obrigações não tratados no estatuto social da companhia, e em parte como um contrato social, uma vez que suas obrigações devem ser observadas não só pelos signatários, como também pela própria companhia e seus administradores, que tem a obrigação de observar o ali pactuado e fazer cumprir o estabelecido no acordo.

Ainda em relação à sua natureza jurídica, a doutrina entende ser o acordo de acionistas um contrato que pode ser unilateral, bilateral ou plurilateral, sendo regido pelas normas de direito civil, em especial as normas que tratam da teoria geral dos contratos, uma vez que o acordo versa sobre direitos e obrigações relacionados aos seus acionistas, e não à sociedade.

Em relação ao seu objeto, ainda que tratados com diferentes nomenclaturas pela doutrina, temos como mais utilizados os acordos que versam sobre o poder de controle da companhia, os direitos dos acionistas minoritários e os acordos de bloqueio, que estabelecem condições para a circulação de ações, como o direito de preferência e opção de compra e venda.

No que tange ao seu prazo e sua forma de extinção, também há de se ressaltar a divergência doutrinária em relação à resilição unilateral, uma vez 
que parte da doutrina entende ser possível a denúncia unilateral, por ser trata o acordo de acionistas de um contrato regido pela teoria geral dos contratos, no qual se aplica o princípio geral no qual contratos celebrados por prazo indeterminado podem ser rescindidos a qualquer tempo, mediante aviso prévio, ressalvando-se que tal rescisão deve apresentar motivo justo, podendo ser contestado pelas outras partes do acordo. Diferentemente disto, outra parte da doutrina acredita não ser possível a celebração do acordo de acionistas por prazo indeterminado, por isto, não se aplicando a denúncia unilateral, por ser totalmente incompatível com o objeto dos acordos de preferência e de opção, que perderiam sua eficácia se fosse possível sua rescisão mediante simples aviso prévio.

Diante de todo o exposto, conclui-se que o acordo de acionistas ainda é um tema bastante controverso para os doutrinadores, existindo divergências decorrentes da análise realizada, principalmente, sob a ótica da doutrina contratualista e comercial, sendo pouco discutido na esfera judicial e na esfera administrativa, não sendo pacífica a escassa jurisprudência sobre o assunto. 


\section{Referências bibliográficas}

BARRETO, Celso de Albuquerque. Acordo de Acionistas. Rio de Janeiro: Forense, 1982.

BORBA, José Edwaldo Tavares. Direito Societário. 14 ${ }^{\mathrm{a}}$ ed. São Paulo: Atlas, 2015.

BRASIL. Lei $n^{0}$ 6.404, de 15 de dezembro de 1976. Dispõe sobre Sociedades por Ações. Brasília: Congresso Nacional, 1976. Disponível em: <http://www.planalto.gov.br/ccivil_03/LEIS/L6404compilada.htm>. Acessado em 18 de outubro de 2018.

Lei $n^{\circ}$ 10.303, de 31 de outubro de 2001. Altera e acrescenta dispositivos na Lei $n^{\circ}$ 6.404/1976 e na Lei $n^{\circ}$ 6.385/1976. Brasília: Congresso Nacional, 2001. Disponível em: <http://www.planalto.gov.br/ccivil_03/leis/LEIS_2001/L10303.htm>. Acessado em 18 de outubro de 2018.

Lei no 5.869, de 11 de janeiro de 1973. Institui o Código de Processo Civil. Brasília: Congresso Nacional, 1973. Disponível em <http://www.planalto.gov.br/ccivil_03/LEIS/L5869impressao.htm>. Acessado em 18 de outubro de 2018.

Lei $n^{0}$ 8.952, de 13 de dezembro de 1994. Altera dispositivos do Código de Processo Civil. Brasília: Congresso Nacional, 1994. Disponível em < http://www.planalto.gov.br/ccivil_03/LEIS/L8952.htm>. Acessado em 18 de outubro de 2018.

Lei $n^{0}$ 13.105, de 16 de março de 2015. Institui o Código de Processo Civil. Brasília: Congresso Nacional, 2015. Disponível em <http://www.planalto.gov.br/ccivil_03/_Ato2015-

018/2015/Lei/L13105.htm>. Acessado em 18 de outubro de 2018. 
BULGARELLI, Waldírio. Regime jurídico de proteção às minorias nas S/A. Rio de Janeiro: Renovar, 1998.

CARVAlHOSA, Modesto. Acordo de Acionistas: homenagem a Celso Barbi Filho. $2^{a}$ ed. São Paulo: Saraiva, 2015.

LAMY FILHO, Alfredo; PEDREIRA, José Luiz Bulhões. Direito das Companhias. $2^{a}$ ed., atual. e ref. - Rio de Janeiro: Forense, 2017.

PENNA, Paulo Eduardo. Alienação de Controle de Companhia Aberta. São Paulo: Quartier Latin, 2012.

ROCHA, João Luiz Coelho da. Acordo de Acionistas e Acordo de Cotistas. Rio de Janeiro: Lumen Juris, 2002. 